\title{
ERNESTO GIMÉNEZ CABALLERO: FASCISMO Y SENTIDO COMÚN EN LA GACETA LITERARIA (1927-1930)
}

\author{
ERENESTO GIMÉNEZ CABALLERO: FASCISM AND COMMON \\ SENSE IN LA GACETA LITERARIA (1927-1930)
}

\author{
Ignacio José HUERTA BRAVO \\ University of Michigan \\ ihuertab@umich.edu
}

\begin{abstract}
Resumen: La Gaceta Literaria (1927-1932) se considera una de las primeras revistas propagandísticas del fascismo en España. Dirigida por Ernesto Giménez Caballero, el ideario de la revista proclamaba una síntesis heterogénea y transversal de nuevas ideologías y manifestaciones culturales que se oponían al viejo establishment. Lejos de ser una doctrina ortodoxa y excluyente, el primer fascismo quería representar la confluencia definitiva de una vanguardia nacional y popular en lucha por la revolución estética y política de la esfera pública española. Conceptos como sentido común, populismo o hegemonía ocuparán este estudio cuyo objetivo es contribuir al debate sobre el discurso contradictorio del naciente fascismo español.
\end{abstract}

Palabras clave: Fascismo. Populismo. Sentido común. Giménez Caballero.
Abstract: La Gaceta Literaria (1927-1932) is considered one of the first propagandist magazines of Fascism in Spain. Directed by Ernesto Giménez Caballero, it claimed a heterogeneous synthesis of new ideologies, literatures and cultural manifestations in opposition to the old-fashioned 
establishment. More than an orthodox and exclusive doctrine, the initial fascism aimed to embody a national and popular ultimate modernism that strived for the political and aesthetical revolution of the Spanish public sphere. Drawing on notions such as common sense, hegemony and consent, this article aims to contribute to the debate on the contradictory discourse of the initial Spanish Fascism.

Key Words: Fascism. Populism. Common Sense. Giménez Caballero.

\section{INTRODUCCIÓN A LOS SENTIDOS COMUNES: DEL REGENERACIONISMO AL FASCISMO}

El siguiente estudio tiene como objeto de análisis los sentidos comunes de los protofascistas españoles, cuya actividad política aún no se había plasmado en una organización con repercusión en la esfera pública española. Es por ello por lo que excluiremos del análisis textos que fueron publicados cuando el fascismo o su vertiente española, Falange Española (FE) de las Juntas Ofensivas Nacional Sindicalistas (JONS) y el partido derivado del Decreto de Unificación FE Tradicionalista de las JONS (1937), ya se habían institucionalizado y formaban parte activa de la propaganda del bando nacional durante la Guerra Civil. La primera pregunta que plantearemos en este apartado es: ¿Qué entendemos por sentido común? Y la segunda cuestión: ¿A qué sentido común apelaba el emergente fascismo español y en qué medida respondía este a la esfera pública moderna? Con relación a la primera cuestión, el sentido común popular es "un agregado heterogéneo" basado en el supuesto de que "el pueblo o conjunto de ciudadanos poseen algo que se llama sentido común, nacido de sus experiencias comunes y de las facultades que comparten como seres humanos" (Nun, 2015: 47-48). Antonio Gramsci lo definió como un conjunto de mitos, leyendas y saberes populares que dan forma a un "agregado caótico de concepciones disímiles" (Nun, 2015: 146). En consecuencia, el uso del término sentido común que nos interesa no refiere a las capacidades cognitivas mínimas que todos compartimos (Ives, 
2004: 74), sino a una constitución heterogénea de elementos populares ${ }^{1}$ que configuran la hegemonía social en la esfera pública moderna ${ }^{2}$. Este agregado heterogéneo no constituye una estructura psicológica permanente, sino que está expuesto a la relatividad histórica y social, especialmente tras los avances tecnológicos, cambios institucionales, migraciones masivas y enormes transformaciones de la subjetividad que tuvieron efecto a comienzos del siglo XX. De este modo, el carácter volátil del sentido común hace del todo imposible formular una definición detallada de sus sedimentos ideológicos. A finales del siglo XIX, la crisis de las identidades colectivas y la ansiedad provocada por la atomización de la sociedad moderna condujeron a las inteligencias europeas a la teorización de los sentidos comunes como ontología de un nuevo objeto sociológico denominado masa. El sentido común popular se sometió a la revisión, transformación, crítica y exaltación de la literatura, la política y la filosofía, no solo para comprender una sociedad gradualmente más heterogénea, sino también para dotar de inmanencia a la misma heurística de los intelectuales, cuyo horizonte teológico era la solución parcial o permanente del problema colectivo (Mosse, 1961: 220-236).

A finales del siglo XIX, los intelectuales pusieron en marcha el proyecto de regenerar el nacionalismo español con el objeto de reforzar un sentido común lastrado por la fuerte crisis identitaria, política y social originada tras la Restauración de 1876 y acentuada tras la pérdida de los últimos enclaves del imperio colonial en 1898. En el Idearium español, Ángel Ganivet apelaba al sentido común nacional para poner en marcha una obra colectiva perdurable en el tiempo. Fue otro regeneracionista, Miguel de Unamuno, quien orientó las bases de un nuevo sentido común que, entre otros, influyó en los primeros fascistas españoles (Saz, 2003).

1. El interés por el sentido común o los sentidos comunes parte de la crítica al discurso pre-constituido u ontológico del marxismo que sostenía que detrás de cada fenómeno social se escondía la realidad de una lucha entre dos clases objetivas. Las significaciones que forman parte del sentido común no están preasignadas a una clase social o un grupo definido, sino que "van emergiendo y mutando en los múltiples espacios en los que se dan los antagonismos" (Nun, 2015: 96). En este sentido, las fuerzas espirituales asociadas a la clase dominante pueden transformarse en impulsoras de las luchas sindicales de los sectores sociales menos favorecidos. Sobre sentido común y marxismo véanse Laclau (1977) y Nun (1988).

2. Jürgen Habermas (1981) define la esfera pública como el espacio político moderno originado de la Ilustración en el que individuos independientes del estado intercambian libremente ideas de modo análogo al libre comercio de productos en las sociedades capitalistas. La idea de una esfera pública racional, libre de restricciones políticas y sociales, es cuestionada por la noción de hegemonía cultural, que plantea la existencia de un consenso en torno a unos sentidos comunes no sujetos a la discusión racional. Como espacio político, la esfera pública viene determinada por conflictos económicos (Eley, 1992), raciales y de género (Pateman, 1988). 
En sus reflexiones En torno al casticismo, publicadas en España Moderna entre febrero y julio de 1895, el escritor vasco planteaba la necesidad de encontrar un carácter nacional que definiera "la realidad viva" de los españoles. En primer lugar, el nuevo sentido común había de promover un proyecto de futuro y no un refugio de historiadores atrapados en el pasado; de "enterradores de osamentas" dedicados a la "arqueología de sombras y de objetos muertos" (Unamuno, 2005: 149-150). Mediante la acción viva se descubriría la verdadera tradición, no la "sombra vana en el pasado" que defendían los conservadores. En segundo lugar, habría de ser un derivado de la "comunión" de los sectores populares y no una tarea dirigida por la política oficial o las élites intelectuales: "un verdadero contrato social intrahistórico, no formulado, que es la efectiva constitución de cada pueblo" (160). Por un lado, Unamuno promovía la vuelta a las esencias del pueblo español: “¡Cuantas cosas cabían en los pliegues de aquel lema: Dios, Patria y Rey!" (267). Por otro lado, manifestaba un entusiasmo por la modernidad que no se vería en su obra posterior. Para Unamuno, el lema de los carlistas significaba, más allá de sus demandas específicas — la instauración de un régimen absolutista y teocrático-, la expresión vital de un Volkgeist español. En último término, consideraba fundamental la generación de un espacio público dinámico adaptado a los tiempos. La sociedad española de fin de siglo, pese a la juventud de su esfera pública, carecía de la energía suficiente para afrontar los retos venideros. El público ${ }^{3}$ moderno español se alimentaba de una prensa que revelaba "la incapacidad indígena de captar directa e inmediatamente el hecho vivo" y que no conocía al público ni creía en él (258); algo que era consustancial a unas élites intelectuales dedicadas "a recoger y encasillar insectos muertos" (150) y unas nuevas generaciones que aceptaban pasivamente el legado de sus mayores y que solo protestaban "en torno a las mesas de café" mientras "al verse en público" se comprimían "como fascinados a la mirada de la bestia colectiva" (256).

Según Unamuno, la esfera pública española, entretenida en estériles y banales discusiones sobre asuntos menores, no se encontraba en condiciones de dar el salto cualitativo hacia una sociedad moderna. Tenía que salir de la autarquía cultural en la que se encontraba para integrarse

3. En referencia a la noción de public o publics veáse Werner (2002: 11-12): “A public enables the reflexivity in the circulation of texts among strangers who become, by virtue of their reflexivity circulating discourse, a social entity". 
en la esfera pública europea. Solo a través de un cosmopolitismo que se nutriera de los caracteres foráneos, y no de una arqueología de las esencias hispánicas, se podría hilar un tejido conjuntivo —el sarcoda - nacional que diferenciara al país del resto de Europa y que a su vez lo propulsara a la misma altura que las naciones hegemónicas. Dos décadas más tarde, José Ortega y Gasset, en el primer editorial, "Propósitos", de la Revista de Occidente, celebraba la configuración de una esfera internacional que ya no promulgaba un pacifismo impostado de preguerra, sino el conflicto abierto entre los diferentes caracteres nacionales. Según Ortega, este contradictorio cosmopolitismo plagado de vocablos de hostilidad estaba facilitando la compenetración y convivencia de Europa. Ortega constataba la paradoja de la internacionalización del nacionalismo: fue la apertura y globalización de las esferas públicas europeas la que facilitó la solidaridad internacional entre organizaciones nacionalistas explícitamente antiinternacionalistas (Mosse, 1961; Conrad, 2010)4 . Aunque llegó más tarde, España no fue una excepción. A finales de los años 20, el quincenario La Gaceta Literaria, sin dejar de ser abiertamente vanguardista y cosmopolita, introdujo el fascismo italiano en la Península Ibérica. El proyecto político y cultural que encabezaba su director, Giménez Caballero, se proponía aunar nacionalismo y modernidad para generar una nueva ideología que vertiera sobre la tradición española el espíritu juvenil de los tiempos.

El fundador de La Gaceta e introductor del fascismo italiano en España, Ernesto Giménez Caballero (Madrid, 1899-1988) consideraba el pensamiento de Unamuno - al que, según el mismo escritor, Malaparte llamó el D'Annunzio español ${ }^{5}$ — un antecedente revolucionario. El autor de La agonía del cristianismo sostenía que España carecía de un espíritu nacional sugestivo, vitalista y plenamente actual, integrado en las corrientes intelectuales y culturales coetáneas. Era, por lo tanto, una labor inútil la copia de programas culturales y políticos extranjeros mientras España careciera de una auténtica sustancia nacional que los nutriera. En líneas generales, el fascismo se postuló como una fe que no necesitaba de un

\footnotetext{
4. En Mosse (1961: 4): "The more urbanized and industrialized society became, the more tended to solidify their world through familiar myths and symbols".

5. La recepción del pensamiento regeneracionista por los fascistas ha sido calificada por numerosos estudios como una manipulación interesada. No es nuestra intención subrayar alteraciones flagrantes o propósitos espurios de los fascistas españoles. Aunque el propio Unamuno, décadas después de sus meditaciones en torno al casticismo, se distanciara de los "fajistas" (Rabaté, 2005: 99), el lenguaje de alto contenido metafórico de sus reflexiones sobre el casticismo hace de todo punto imposible una recepción auténtica de su pensamiento, de modo que los desplazamientos semánticos son inevitables.
} 
programa previamente teorizado, cuya constitución ideológica se produjo de forma reactiva, vertebrándose a través de situaciones contingentes que se ungían de una retórica totalitaria. Una doctrina sin doctrina que se sabía revolucionaria no tanto por sus objetivos indefinidos, como por sus métodos activos. Especialmente antes de institucionalizarse, el fascismo fue una ideología en constante movimiento argumental y retórico cuya política se sostenía en la exaltación de la acción en la calle; el espacio hegemónico del conflicto político moderno.

En los prolegómenos de la década de 1930, los fascistas españoles concentraron sus esfuerzos en cimentar una ideología nacional y transversal plenamente integrada en el sentido común de la España moderna que, sin caer en el tradicionalismo conservador, actualizara el pensamiento regeneracionista de finales del siglo XIX para asimilarlo a las tendencias políticas y culturales continentales. Durante la primera etapa de La Gaceta Literaria, que hemos establecido entre la fecha de su primera publicación, en 1927, y 1930, cuando se produjo la ruptura política entre buena parte de sus colaboradores, la retórica fascista de Giménez asimiló un conjunto de elementos muy heterogéneos —regeneracionismo, vanguardismo y antieuropeísmo (Selva, 1999) - cuyo denominador común era una rebeldía juvenil contra la vieja cultura política y literaria: organizaciones intelectuales, medios de comunicación, estamentos tradicionales $\mathrm{y}$, en su conjunto, todo lo que no formaba parte activa de la nueva esfera pública española fueron el blanco de su pluma. Este periodo es conocido como la vía estética del fascismo en España ${ }^{6}$ y antecede al movimiento que encabezó Ramiro Ledesma Ramos y la revista que fundó en 1931, La conquista del Estado. Finalizada la dictadura de Primo de Rivera, el filósofo zamorano puso en marcha un proyecto político alternativo que aprovechase el desconcierto de la conflictiva esfera pública española con el fin de acabar con las viejas instituciones, así como con cualquier otro orden posmonárquico fundamentado en los principios demoliberales del siglo XIX. En el siguiente capítulo abordaremos la etapa de La Gaceta Literaria, protagonizada, aunque no exclusivamente, por Giménez Caballero y veremos de qué manera trató de concebir una ideología

6. Sobre la vía estética del fascismo véanse Pastor (1975) y Selva (2005: 69-108). Para un estudio más detallado de los escritores españoles de vanguardia vinculados al fascismo véase Mechthild (2003). Por último, un interesante análisis de la estética vanguardista en el pensamiento de Ramiro Ledesma Ramos lo constituye Gallego (2005). 
transversal al sentido común de su época.

\section{LO NUEVO Y LO VIEJO}

Ortega dio paso al primer editorial de La Gaceta Literaria proclamando la superación de los moldes intelectuales y políticos decimonónicos y la incorporación de un pensamiento español revitalizado al mundo. Según el filósofo madrileño, el objeto de La Gaceta como órgano cultural vanguardista era dejar a las letras españolas a la zaga de las corrientes literarias e intelectuales del mundo $(1)^{7}$. La revista se constituyó como un medio de promoción de la vanguardia y del espíritu juvenil de los tiempos que hacía gala de un carácter notoriamente frívolo e irreverente en el tratamiento informativo de los personajes, grupos y fenómenos que ocupaban sus páginas. El objetivo era agitar el anquilosado y provinciano panorama cultural: "mi propuesta — señores asambleístases la de tocar un poco el pito a todos ustedes (o a todas vuestras señorías, como tan bien suena en este salón de las pomposidades, las elocuencias y las ineficacias)" - escribía Giménez satirizando la discusión entre los asistentes a la Asamblea Nacional del Libro. Contrario a los argumentos y modos decimonónicos de la Asamblea, el escritor madrileño sostenía que la regeneración de las letras españolas no era un asunto de "editores y libreros", sino una tarea reservada a los escritores noveles, a los cuales comparaba con "un motor de posibles grandes vuelos" (37). Giménez o Gecé, su pseudónimo vanguardista, criticaba la cultura de la intelectualidad española por su falta de dinamismo y perspectiva internacional. Despreciando el ánimo divulgativo y enciclopedista de otras publicaciones culturales, La Gaceta no era ni pretendía ser una plataforma proveedora de desinteresados contenidos literarios e intelectuales, sino, como su mismo subtítulo indicaba - ibérica-americana-internacional-, un medio activo de lucha por la hegemonía cultural nacional e internacional.

La revista se incorporó a la esfera pública del periodo de entreguerras, la cual, según hemos apuntado anteriormente, presentaba hostilidades nacionales que se alimentaban recíprocamente. Un caso particular de esta esfera conflictiva fue la controversia entre La Gaceta y la revista argentina

7. Todas las citas de los artículos de La Gaceta corresponden a la edición facsímil de La Gaceta Literaria I, números 1-72, Madrid (enero 1927-diciembre 1929). Vaduz: Topos Verlag AG, 1980. 
Martín Fierro sobre el papel hegemónico de Madrid como meridiano de las letras hispanoamericanas. Tras la misiva de la publicación bonaerense cuestionando la aportación de los escritores madrileños a la literatura hispanoamericana, Giménez respondió de forma desenfadada que, en primer lugar, el espíritu bélico de las nuevas juventudes españolas no tenía miedo a la confrontación y, en segundo lugar, que, ante los ataques de la vieja élite intelectual, convenía adoptar una posición acorde con los tiempos y el espíritu de La Gaceta: "a las actitudes rígidas y deficientes, un poco de buen humor y de risa" (101) —apostillaba el madrileño. El titular del editorial del siguiente número, "La verbena del meridiano" (105), con el que La Gaceta cerró la controversia con Martín Fierro, no deja lugar a dudas al respecto. Decía Gecé de Ramiro de Maeztu que el lado dogmático y serio del intelectual nacional, especialmente si el escritor es hispánico y vive en el barrio de Salamanca, suele vencer sobre su lado popular (19). Los modos soberbios son propios de la vieja España, no así del carácter popular de la joven España que, acorde con su mundo oscilante y cambiante, afronta la falta de certidumbres de la nueva época con buen humor y sin excesiva seriedad.

Otra de las expresiones de lo viejo era la política oficial. Como han señalado otros autores, La Gaceta marcó la transición de una vanguardia desinteresada de la política a otra comprometida (Geist, 1980; Selva, 1999). El paso de la vanguardia al compromiso no fue tan brusco, sobre todo para aquellos intelectuales y literatos que luego se hicieron fascistas o comunistas. El desinterés por la política de la generación de Gecé no era otra cosa que el desprecio a la vieja casta que, desde 1876, se había turnado en el poder, olvidándose de las masas y del pueblo. La rotundidad con que otro de los colaboradores habituales, que ejerció también como secretario de La Gaceta sustituyendo a Guillermo de Torre, Cesar María Arconada (1898-1964), negaba la connivencia entre política y la literatura - "No. No. No" - no era una llamada a la enajenación social del escritor, sino, al contrario, un rechazo de la política entendida como el coto privado de una burguesía liberal que se encontraba "en el desván, a punto de ser retirada de la circulación del mundo"- (153). Contraria a la política liberal y conservadora, la línea editorial de la revista estuvo siempre preocupada de formar parte del sentido común de su época: por un lado, el de las masas que surgieron con la modernización económica del país - como públicos extraños entre sí- y, por otro, el del pueblo — la comunidad 
intrahistórica de Unamuno- que acudía entusiásticamente a las fiestas populares, las verbenas y las corridas de toros. Los jóvenes escritores se inspiraron en el agregado caótico denominado cultura popular que surgió de las transformaciones, resistencias y contingencias sociales, políticas y económicas de la modernidad (Hall, 1998; Nieland, 2008). La literatura era la expresión de un sentido común en el que confluían modernidad y tradición, vanguardia y 98, novedad y folclore, masa y pueblo. En oposición a su antagonista, la política oficial, la literatura expresaba el sentir del auténtico pueblo. Para Arconada, solo había dos movimientos extraliterarios contrarios al statu quo que lo habían entendido: el comunismo y el fascismo. Gecé vio el último como el desencadenante necesario de todas aquellas expresiones contradictorias de la modernidad; una tercera vía entre la vanguardia y la tradición: el "vino revolucionario en odres tradicionales" (Giménez Caballero en Selva, 1999: 88). En una carta a Giménez publicada en La Gaceta en marzo de 1928, el escritor y periodista y, al acabar la Guerra Civil, primer director del Instituto Italiano de Cultura de Madrid, Ettore de Zuani (1897-1953) justificaba el movimiento liderado por Mussolini ante los ataques de los medios internacionales por ser no "tanto política, como sobretodo fe, entusiasmo, pasión; y eso no lo podemos olvidar ni siquiera cuando hacemos literatura" (187). Una doctrina sin doctrina acorde con la forma de sentir y de ver el mundo de las jóvenes generaciones literarias.

\subsection{Lo nuevo y lo viejo: ultraísmo y fascismo}

“Un más allá, juvenil y liberador" (47) con "un sentido del humor cósmico" (42) que era una "violenta reacción contra la era del rubenianismo agonizante" (46). Así se expresaba el secretario de La Gaceta, Guillermo de Torre, al contraponer en Literaturas europeas de vanguardia (1925) la literatura contemporánea a la del periclitado modernismo. Torre fue el artífice del ultraísmo, un movimiento aglutinador de "todas las tendencias estéticas mundiales de vanguardia" (48) en el que afluían el belicismo y el activismo que las caracterizaban, pero también la frivolidad, la espontaneidad, el gusto por lo no convencional, así como un humorismo irreverente. Para Torre, el iniciador y referente del ultraísmo fue su amigo y también colaborador habitual de La Gaceta, Ramón Gómez de la Serna. "Si bien no se puede decir que el mundo es un disparate, el pensamiento 
del hombre y el alma humana son unos puros disparates" (5) - afirmaba Gómez de la Serna en la estridente disertación teórica que prologa sus Disparates. El creador de la greguería tuvo una enorme repercusión en la síntesis que Giménez trató de llevar a cabo entre la vanguardia juvenil y relativista con la que se identificaba - la del disparate y la greguería - y el nacionalismo de las viejas instancias intelectuales del 98 (Mainer, 2005). La atropellada, ansiada y, en muchos casos disparatada convergencia entre modernidad y nacionalismo de Giménez, le debía mucho a un declarado apolítico como Gómez de la Serna. Años antes del proyecto políticoliterario de Gecé, el líder de la tertulia del Café Pombo celebraba en sus Disparates la transformación del espacio público español. Por un lado, las alteraciones provocadas por el tránsito de España hacia una sociedad de masas de la que querían ser parte activa todos los estratos sociales. Ejemplo de ello es la caricatura de una revolución que tiene lugar en una plaza de toros en la que el público, liderado por el primer espada, se rebela contra el presidente (34). Por otro, la recepción masiva de novedades (Highfill, 2014) en relación con las antiguas fiestas populares. Esto lo refleja en la disparatada imagen del cine como un corral de comedias en el que ya no hay gallinas, sino gallos "que las noches de luna se proyectan sobre la pantalla cinematográfica de la noche y cacarean numerosas ¡BU-E-NAS NO-CHES!" (13-14). En sus apologías del fascismo, Giménez plasmó el sentido desenfadado y burlesco expresamente ramonista, asociando afanosamente elementos anacrónicos de difícil maridaje con el objeto de, en primer lugar, refundar los mitos nacionales en la modernidad y, en segundo término, crear un ultraísmo ideológico y estético que aglutinara la práctica totalidad de lo nuevo. Un proyecto sintético de tradición y modernidad que ya había comenzado años antes, en Notas marruecas de un soldado (1923):

Pero vayámonos, también, orientándonos, medievalistas, estudiosos de la épica [...] hacia el género donde ha evolucionado, en sustancia, la poesía de los romances. $Y$ es el cinematógrafo. No es accidental que las judías de Xauen narrasen, a la par, las proezas del Conde Claros y de Douglas Fairbanks (1983: 143).

En el mismo pasaje de las Notas marruecas, Giménez reclamaba la 
necesaria aparición de un "nuevo Cervantes del film" que le diera a España un auténtico cine nacional. Al referirse al entusiasmo que les provocaba Fairbanks a las judías de Xauen, Giménez acusaba la paradoja de que un elemento foráneo producto de la modernidad como el cine - el espacio público de recepción y producción masiva e internacional de imágenes compartidas por públicos extraños entre sí- activaba los sentimientos de pertenencia e identidad entre los espectadores. Este ejemplo demuestra que el desarrollo de la producción internacionalizada y los nuevos modos de recepción masivos nunca estuvieron en contradicción con los procesos de identificación míticos y nacionales (Berman, 1989: 35-41), sino que, como quería demostrar Gecé, podrían ser un instrumento idóneo para reforzar los vínculos nacionales entre la población del Rif y la península ibérica ${ }^{8}$. Adoptando la sintaxis vanguardista —el lenguaje plagado de neologismos, la yuxtaposición de elementos contradictorios y el párrafo corto culto a la emergente sociedad del espectáculo de la literatura ultraísta, $L a$ Gaceta continuaba el proyecto de Notas marruecas de integración del nacionalismo español en la modernidad. De modo similar al disparate ramonista, Giménez aclamaba a Don Juan Tenorio por ser el recordman del amor (237) o a Santa Teresa como la Mujer-Musa del sindicalismo obrero (465); haciendo un juego de palabras con el hombre-masa de Ortega.

Su conversión al fascismo no excluyó este tipo de asociaciones disparatadas, sino que, al contrario, la ideología mussoliniana fue el leitmotiv perfecto para desarrollarlas sistemáticamente. Merece especial atención las cartas de "La etapa italiana" fechadas el primero de agosto — "12.203 Kilómetros de literatura" (246) —, el 15 de agosto — “12.203 Kilómetros de literatura. La etapa italiana" (252) - y el 1 de septiembre — “12.302 Kilómetros de literatura. La etapa italiana" (260)— de 1928. En la publicada el 15 de agosto, Gecé describía a Benito Mussolini como la encarnación de lo aristocrático, pero también del espíritu popular y plebeyo de la Italia subalterna. Giménez representaba al duce como un emigrante de origen plebeyo y un arribista; un robanidos en su infancia

8. Los nuevos espacios públicos reprodujeron con más fuerza si cabe el culto, el ritual y la doctrina de las religiones secularizadas que conocemos como ideologías. El fascismo es el paradigma recurrente de la estetización de la política, algo que no excluye otros los discursos hegemónicos; no solo a los considerados como populistas ni a los reducidos al ámbito de la política institucional o de la educación — los aparatos ideológicos del Estado que definiera Louis Althusser-, sino también a los que actúan fuera del debate público: los de las empresas de mass media, los de la publicidad, los productos culturales de gran difusión, etc.

9. Interesantes trabajos sobre la prosa vanguardista de Giménez se pueden encontrar en Dennis (1991) y Anderson (2002; 2011). 
y un buscavidas en su juventud que había tenido que emplearse en todo tipo de menesteres. Una imagen todavía más chocante de Mussolini nos la ofrece al decir que el dictador es la síntesis de César y Charles Chaplin; el emperador de la nueva Italia y el bufón de las masas populares. Aunque en un contexto completamente diferente, esta disparatada asociación de imágenes, que difícilmente se puede atribuir a un convencido partidario del fascismo, conservaba muchas similitudes con los collages burlescos que, en el número dedicado al carnaval, hizo La Gaceta a diversas referencias de la literatura contemporánea: Paul Valery, travestido de gitana, José María Pereda, haciendo de improvisado boxeador o Ramiro de Maeztu, de socialista (25). La Gaceta se hacía eco de referencias políticas y literarias que, al tiempo que eran exaltadas y magnificadas, también eran objeto de comentarios burlescos. Ejemplo de ello era la sección realizada en coautoría con Arconada, Giménez, Gómez de la Serna y Torre, "Manías de los escritores", que, en tono jocoso e histriónico, presentaba el lado más personal de las vacas sagradas de la literatura española: Juan Ramón Jiménez era un "lepidóptero asocial" que no quería tener contacto con sus vecinos (43); Ortega, un maniático de la velocidad y del progreso que recorría con su automóvil los páramos atrasados de Castilla (31); o Pío Baroja, víctima de su propia manía hacia los judíos al ser mordido por su perro Thor, apodado como el dios de la mitología aria (99).

Empero, el paralelismo entre Chaplin y Mussolini es algo más que un hilarante disparate. Recordemos que la película El circo (1928), protagonizada por el mismo actor, tuvo una entusiasta acogida en la $L a$ Gaceta $^{10}$. En un articulo dedicado a la película, Giménez rendía culto a la figura individual de Chaplin por conciliar a públicos antagónicos como las masas y las minorías, lo que confería al actor el carácter trascendental de "un ideal sintético a priori. Eso es. Un mito: una fabulosidad" (188). A continuación, Gecé definía el circo como un espacio público que generaba consenso entre las clases bajas y las burguesas; entre la masa irracional y las élites intelectuales. "Pueblo" e "Inteligencia" acudían fraternalmente a un lugar reservado al entretenimiento:

Mientras los niños y los obreros y el burgués, a nuestro

10. Primero de la mano de Luis Buñuel y luego de Antonio Piqueras, el cine tuvo siempre un lugar privilegiado en la revista (Gubern, 1999: 202-207). 
lado, reían con sus vientres tiernos e inocentes, reía nuestro cerebro con claridad y sonrisa metálica y pura.

Fue un experimento de alta tensión. De suprema fraternidad entre clases humanas. Vientre popular y médula de minoría. Folklore y Matemática (188).

Para Michel Foucault, el soberano tiene un lado grotesco que, lejos de minar su autoridad, enfatiza y refuerza su poder reconociendo implícitamente su carácter contingente al decir yo también soy un humano como vosotros. La conjunción entre lo cómico y lo épico elevaba simbólicamente a las clases populares al lugar otrora reservado a las viejas élites. Tanto en Chaplin como en Mussolini, la estridencia no está en contradicción con el heroísmo. O por decirlo de otro modo, en el circo, como en el estado fascista, vientre e inteligencia se dan las paces. En este sentido, el fascismo de La Gaceta, lejos de ser una respuesta reaccionaria a las transformaciones del mundo contemporáneo, quería representar una modernidad alternativa (Griffin, 2007) que, adaptándose al sentido común de la sociedad de masas, desencadenara una revolución consensuada y sin antagonismos de clase. Cuando nos referimos a una ideología consensuada, lo hacemos en el sentido gramsciano ${ }^{11}$. No se trata de un consenso formulado de acuerdo a dos diferentes partes que establece una relación de reciprocidad mutua, sino en lo que Ortega denominara, en España invertebrada (1922), como un proyecto político sugestivo y no coercitivo para captar a las masas. Gecé privilegió la dimensión afectiva como un elemento de unión interclasista para la transformación social. No está de más decir que Gómez de la Serna también quería convertir el mundo en un circo (Dennis, 2002: 115). Aunque sin la significación ideológica del autor de Notas marruecas, ambos escritores compartían el deseo de estetizar la sociedad. Cuando Giménez se refería al fascismo como un vino revolucionario en odres tradicionales, constataba el desplazamiento afectivo de los lugares rituales tradicionales a los de la nueva sociedad de masas. En otras palabras, el circo simboliza la confluencia de los nuevos modos de recepción estética, los espacios públicos y los sujetos políticos derivados de la misma. No obstante, no podemos limitar esta celebración

11. Sobre la concepción gramsciana de consenso como mecanismo de integración ideológica para la alcanzar la hegemonía cultural en las sociedades occidentales modernas véase Thomas (2009: 159-162). 
de la dimensión afectiva de la sociedad al fascista de Giménez, ya que una gran parte de los escritores que colaboraron con La Gaceta aplaudieron entusiásticamente la estetización de la política en los nuevos espacios públicos: el circo, el teatro, el cine, la plaza de toros o el estadio de fútbol.

\subsection{La nueva política: la conquista de las masas}

Como hemos observado, La Gaceta fue una plataforma de recepción y asimilación de contenidos muy heterogéneos que la convirtieron en algo más que una revista de vanguardia (Moreno-Caballud, 2010: 431). En particular, los editoriales de su director alternaban varias disciplinas con dosis de cultura popular sin rigor cronológico ni explicación diacrónica que, de forma similar a los manifiestos de las vanguardias históricas, proclamaban un antagonismo radical entre un ellos y un nosotros en todos los niveles de la esfera pública (Caws, 2001: XXII-XXIII). Los editoriales de La Gaceta exaltaban la modernidad y la pureza de la política totalitaria, antónimo de la decadente y corrompida sociedad española. La crítica alcanzaba tanto a las élites - el clero y ejército — como a las clases medias de asalariados y funcionarios que aceptaban pasivamente la situación. Del mismo modo que Unamuno, La Gaceta señalaba como culpables de la situación española a aquellos elementos residuales de la sociedad derrotista de finales de siglo culpables de la reproducción de hábitos de inactividad y conformismo social: "el sentido del bar [...] de la merienda y de la cuchipanda"; de la "butaca y el café, el limpiabotas y el cigarrito" que descansaba, engordaba, se abanicaba (252); y un joven español "que hoy siente adormecidos sus instintos brutales y agresivos, por tantos años de burocracia pacifista, de militarismo oficinesco, de predominio oficial de los viejos, de los ramplones, de una clase media estricta" (246). A diferencia de su homólogo mediterráneo, el estado autoritario italiano había revitalizado la esfera pública: "lejos de toda oficina, de toda covachuela, de todo destinejo ministerial, en plena vía férrea, en pleno periodismo audaz, en plena frontera, en plena alta hora de la noche, en plena tensión vigilante y dominadora" (246). Para Giménez, la dictadura de Miguel Primo de Rivera no solamente no había transformado la esfera pública, sino que su acción "pacifista" había agudizado el decadente demoliberalismo burgués del siglo XIX. Por el contrario, recuperar la dimensión afectiva de la sociedad 
moderna ${ }^{12}$ - la del cine, la propaganda, la publicidad—, sacudir los lastres de la antigua esfera pública — la del café, la tertulia y el abanico- y, en último término, invadir el ámbito autónomo del poder eran elementos de un programa transversal comprometido con el dinamismo de la modernidad que compartían muchos de los vanguardistas que se politizaron a fines de los veinte, entre ellos, el más tarde militante comunista, César María Arconada:

De la multitud ardorosa de los estadios, como de la multitud religiosa de los cines, ha de salir el mundo nuevo, el mundo de nuestra época. Frente al café, la tertulia, la política, el teatro, exaltemos nuestras cosas: el cine, la acción, los deportistas, las mujeres con pelo corto. Frente al artista, al político o al cómico, exaltemos al nuevo héroe: al futbolista, al boxeador, al chófer (143).

Esta exaltación de la nueva la esfera pública no solo se remitía a las masas organizadas en los partidos y sindicatos, sino al hombre-masa de Ortega, que no se limitaba a una sola clase social subalterna. Para el autor de La rebelión de las masas (1930), se trataba de un sujeto social moral y cualitativamente menor derivado de la esfera pública capitalista, que ofrecía un consumo sin límites de bienes y servicios. Al creerse con derecho a todo, ningún obstáculo material o espiritual impedía al hombremasa demandar una participación activa en política e incluso suplantar a las minorías gobernantes. La intromisión de la masa y los valores negativos asociados a ella — la vulgaridad, la mediocridad y la indiferencia - en todos los ámbitos de la sociedad desembocaría necesariamente en el fin de la política como una actividad exclusiva de las minorías egregias: los individuos diferenciados por su cualificación técnica y superioridad moral. En consecuencia, la plenitud ideológica del sentido común de la masa llevaría a la sociedad avanzada, que le había dado las herramientas técnicas, materiales y legales para prosperar, a su completa destrucción, a la barbarie preexistente. Según Ortega, históricamente la masa se había

12. Nieland (2008) desarrolla el concepto de publicness, que define la actuación política de los vanguardistas (modernists) para recuperar una dimension afectiva de la esfera pública. 
hecho con el poder en Rusia y en Italia, otro país mediterráneo como España en el que, aun manteniéndose las viejas instituciones burguesas, el poder actuaba con el mismo ánimo anárquico de la masa. Para Ortega, el problema del fascismo no era tanto la brutalidad de sus métodos represivos, como la instauración, aunque transitoria, de la masa dentro del poder. Es decir, la barbarie, la anarquía y el odio a la aristocracia se insertaban en la máxima expresión de la civilización: el Estado. Aun manteniendo las antiguas instituciones y legislaciones, el poder perdía su función rectora y ejemplarizante esforzándose por actuar con la irracionalidad de las masas. Giménez llevó esta polémica a las páginas de La Gaceta. En oposición al elitismo liberal de Ortega, Gecé sostenía que el hombre-masa "quizás no es tan masa y seguramente es más hombre que los de otras épocas históricas" (465).

Como hemos mencionado anteriormente, Giménez representaba a santa Teresa como la "Mujer-Musa" que "si se me permitiera decirlo" diría que es "sindicalista", porque nadie era "más popular que ella" y "nadie estaba más metida en la masa" que la fundadora de las Carmelitas Descalzas. Esta yuxtaposición tan profundamente literaria entre la época imperial y la acción revolucionaria de los sindicatos quedaría patente en la enseña falangista creada por Ledesma y por el mismo Giménez cuando, según cuenta en sus Memorias de un dictador (1979), estaban cerca del ateneo libertario y vieron cómo ondeaba la bandera rojinegra anarquista. Los fundadores del nacionalsindicalismo colocaron sobre el rojo y negro de la bandera de la Confederación Nacional del Trabajo el yugo y el haz de flechas de los Reyes Católicos, nacionalizando de esta forma el sindicalismo revolucionario. Este símbolo, para nada relacionado con la vanguardia, se origina en un gesto de incuestionable frivolidad vanguardista.

\subsection{Antieuropeísmo y casticismo}

Ortega consideraba que el fascismo y los episodios revolucionarios que auparon la masa al poder eran propios de sociedades periféricas cuyos caracteres estaban moldeados por la irracionalidad de Oriente, en el caso de Rusia, y del Mediterráneo, en el de Italia. Desde Arconada al conde Keyserling, La Gaceta recibió con optimismo el despertar de las naciones europeas que habían adoptado modelos políticos alternativos a la democracia liberal. Las tesis de Curzio Suckert, alias Malaparte, y su 
libro Italia barbara (1925), que achacaba la subalternización cultural y política del sur de Europa a la hegemonía protestante, tuvieron una fuerte repercusión en el viraje político de la revista. Tal fue su influencia, que no sería excesivo considerar el pensamiento político de Giménez, desde su prólogo a Italia barbara "En torno al casticismo de Italia. Carta a un compañero de la joven de España" publicado en La Gaceta hasta su opera prima Genio de España: Exaltaciones a una resurrección nacional y del mundo (1932), una adaptación a la española de Malaparte a golpe de greguería. En el primer periodo que estamos analizando, el fascismo español se identificaba con los movimientos políticos italianos y rusos por ser modelos de "una política original y sin préstamos nórdicos" (173). En los mismos términos, Giménez hacía una apología de lo moro y lo africano por contraponerse a lo ario; raza que extendió el espíritu racionalista hegemónico por Europa. En la "Carta a un compañero de la joven España", fechada el 15 de febrero de 1929, Giménez apoyaba la petición de un joven español "embebido de tradición germanizante y occidentalizante" de crear un movimiento fascista a la española "de Sur contra Norte": "¡No somos europeos!"- exclama. En conclusión, la carta apela a la confluencia de todos los pensamientos, ideas y manifestaciones de la España moderna contra el orden turnista que había fracasado en su proyecto de europeizar a un país periférico como España. Un risorgimento nacional que uniera en un haz las diferentes generaciones: la del 98 de Unamuno, la novecentista de Ortega y la vanguardista de Gómez de la Serna.

Sin embargo, el fascismo transversal de Giménez contenía tales contradicciones que difícilmente podía ser el inicio de un proyecto nacional-popular. En el año 1928, Gecé alternaba la defensa del catolicismo hispánico con el pansexualismo de Yo, inspector de alcantarillas, un libro caleidoscópico en el que narraba, tabúes aparte, relaciones zoófilas, sacrilegios y actos onanistas ${ }^{13}$. Cierto es que la defensa de la catolicidad de Giménez no denunciaba una sociedad secularizada en la cual la Iglesia había perdido su papel rector en la sociedad, sino que respondía fundamentalmente al antieuropeísmo de Malaparte. Según el autor de Italia barbara, el espíritu racional e ilustrado decimonónico había suplantado el vitalismo y la irracionalidad de los países católicos

13. Sobre lo escatológico de Giménez en su etapa vanguardista y su relación con el fascismo véanse, Labanyi (1996), Pino (2004), Krauel (2006) y Pao (2010). 
del sur de Europa. Cuando Giménez se refería al psicoanálisis en su Yo, inspector defendía que no era otra cosa que una manifestación más de la mística nacional. La asociación de misticismo y psicoanálisis ejemplifica perfectamente la retroalimentación contradictoria del pasado y el presente en un nacionalismo que no rechaza la modernidad, sino que se reproduce en todo fenómeno actual.

\subsection{Casticismo y modernidad en Esencia de verbena}

El fascismo es una religión secularizada que transfiere los espacios de culto de sus antiguos lugares sagrados a la esfera pública (Berezin, 1997). Una religión que basaría su poder ideológico en tres niveles: 1) una religión-sucedáneo implementada por los aparatos coercitivos de un estado totalitario (Linz, 2006); 2) una comunidad en el que sociedad e instituciones estatales se abrazan conmemorando una fiesta nacional; y 3 ) una manifestación de ritos y hábitos consentidos en la sociedad de consumo. En términos gramscianos, una hegemonía localizada en el consenso de la sociedad civil y no en la fuerza del poder coercitivo (Ives, 2004: 121-122). Del mismo modo, la intrahistoria de En torno al casticismo interesó a los primeros fascistas españoles por su eficacia ideológica, que reside más en su valor consensual de sentido común desde abajo, que en el de una doctrina propagada desde arriba: el "verdadero contrato social no formulado que es la efectiva constitución de cada pueblo" (Unamuno, 2005: 160). La Gaceta promocionó la cultura del consenso de los felices años 20: el charleston, las fiestas populares, el circo, el star-system hollywoodiense y los deportes. En la mayoría de los casos, productos culturales importados de la industria americana, que formaban parte de lo que Clement Greenberg llamara en 1939 la cultura kitsch ${ }^{14}$. El fascismo vanguardista de La Gaceta festejaba los mecanismos de producción sensitiva de la sociedad de consumo. No los contraponía necesariamente con un estado fascista, porque este último hacía de la política un espectáculo, la estetizaba. La política, otrora recluida en los parlamentos, templos del liberalismo decimonónico, ahora se expandía al estadio, la sala de cine y la verbena. En este sentido, el fascismo sería una teología política que no renuncia a la satisfacción libidinal y el disfrute

14. Serrano y Salaün (2006: 88) subrayan la proliferación de películas de Hollywood en la segunda mitad de la década de 1920 en detrimento de una producción cinematográfica nacional en constante declive. 
masivo de la esfera del consumo. El culmen de la síntesis nacionalista de la vanguardia, la nueva esfera pública, las masas y la política fue la película del Cineclub de La Gaceta: Esencia de verbena (1930). Este cortometraje de apariencia y realización improvisadas es de una gran densidad simbólica. En la película operan una serie de significantes que hacen del fascismo un proyecto inclusivo de masas, vanguardias artísticas y políticas. El título se fundamenta en la síntesis de un mundo moderno del hombre-masa oscilante y frívolo y el Madrid castizo de fiestas y tradiciones eternas. En el cortometraje sobre las verbenas de San Antonio y de La Paloma, los planos de botijos "milenarios" y los churros "de abolengo moruno" son la esencia permanente de una verbena cuyos artefactos - la noria, el tiovivo o el tubo de la risa - reproducen el ritmo desenfrenado, oscilante y giratorio de los tiempos modernos. El tiempo pasajero del "humo" de las cigarreras del Rastro actualiza otro tiempo mítico: el humo de la parrilla en la que se martirizó a San Lorenzo. La verbena forma parte del sentido común popular moldeado por el dinamismo vertiginoso de una emergente sociedad de consumo en la que, no obstante, se manifiesta un Volkgeist madrileño. Lo popular abarca un amplio campo semántico en el que la tradición convive y se transforma con los nuevos modos de producción e intercambio. Un nacionalismo en sintonía con el ultraísmo de Torre: "júbilo dyonisiaco o, más bien, sentido del humor cósmico, afirmación occidental, exaltación de nuevos valores vitales" (42). Es decir, un ultraísmo político que fuera la apoteosis, no solo de las vanguardias de principios de siglo, sino también de los movimientos políticos y culturales que se sucedieron desde finales del siglo XIX: regeneracionismo, novecentismo, etc. Esencia de verbena fue uno de los últimos intentos, también fracasados, que hace Giménez de configurar una ideología popular y espontánea que se antepusiera a una doctrina definida (Žižek, 1994; Laclau, 2014). La disposición caótica de un repertorio simbólico tan heterogéneo conllevaba el sueño fascista de una comunidad intrahistórica — tradicional y moderna - que, formada desde el consenso de la base social, partiendo de los sentidos comunes, superara todas las contradicciones sociales, políticas y nacionales. 


\section{CONCLUSIONES: EL FASCISMO DE LA GACETA LITERARIA Y EL PROYECTO POPULISTA POSMONÁRQUICO}

Dos años antes de la formación de Falange Española, a finales de 1933, Ramiro Ledesma Ramos fundó el semanario La conquista del Estado. Tras proclamarse la Segunda República, el filósofo zamorano sostenía que el 14 de abril era una oportunidad de ruptura con la vieja política demoliberal. Pensaba que lo que se estaba dirimiendo durante aquellas fechas era la lucha de una España vieja contra otra nueva, de la que posteriormente saldría el vencedor de las únicas vías posibles frente a la decadencia del sistema capitalista: el fascismo y el comunismo. Sin embargo, las primeras hostilidades entre el catolicismo y el republicanismo generaron un antagonismo en el que el fascismo, como ideología revolucionaria y transversal, tendría un papel subalterno. En los años siguientes, el fascismo español pasaría a las filas de los sectores conservadores antirrepublicanos adquiriendo un rol gradualmente más relevante en la esfera pública. Con relación a este último periodo, es necesaria la elaboración de un estudio completo de los elementos de sentido común durante la Segunda República hasta y después del estallido de la Guerra Civil. Un buen inicio es el trabajo de Rafael Cruz (2006; 2013), que observa el enfrentamiento político entre el republicanismo y los sectores contrarios al cambio de régimen a partir del análisis de la construcción social imaginada de un pueblo y un contrapueblo durante la República. Desde este referente, debiéramos considerar un estudio más completo de la literatura y la política vanguardista, y su relación con esta construcción social o comunidad imaginada (Cruz, 2013: 113).

De acuerdo con nuestra exposición, el tránsito ideológico de una "interpretación nacionalista liberal de España" (Mainer, 2005: LII) al fascismo excluyente que Giménez manifestara en el periodo republicano no es una evidencia constatable. Con la caída del régimen alfonsino y la redefinición de los antagonismos, los disparates del escritor madrileño fueron sintonizando con el bloque antirrepublicano que se configuró antes del estallido de la Guerra Civil. Para analizar esta transición, debemos excluir como marco analítico la simple oposición entre un liberalismo nacional integrador y aglutinador de diferentes sensibilidades ideológicas y un fascismo excluyente, fanático y ortodoxo. La transversalidad, heterogeneidad y pluralidad de ideologías de que acogió La Gaceta fue 
el punto de partida del fascismo de Giménez. Al definir el fascismo como una política de consenso, nos referíamos a que su eficacia persuasiva se encuentra en el terreno de los sentidos comunes y no solamente en el de la violencia y la coerción. Ortega sostenía que el fascismo era una síntesis compleja y contradictoria de $A$ y no- $A$ que promulgaba simultáneamente la defensa de la tradición y de la modernidad. Por eso hemos titulado nuestro estudio fascismo y sentido común, porque en un momento de decadencia de las viejas instituciones, Giménez creó el proyecto político-literario de La Gaceta "excluyendo toda exclusión" al imaginar una comunidad plena en la que participan los ultraístas, los catalanes, los socialistas, los sefardíes, los regeneracionistas, los surrealistas, los industriales, los obreros, los burgueses etc. Un cómodo antagonismo entre lo nuevo y lo viejo que señalaba como enemigo un demoliberalismo que estaba en franca decadencia y crisis en toda Europa. El fascismo español fue menos pluralista (Payne, 1999: 52) en la medida en que se definían los antagonismos que establecieron la relación entre la política, la sociedad y las letras durante la República.

Entendemos el populismo como la forma de hacer política que establece una frontera definida entre un ellos y un nosotros. Sin embargo, el populismo no es simplemente la ideología liderada por un mesías cuya secta de fanáticos se erige como la voz del pueblo. En el momento en que se define con esto caracteres el populismo es: a) un fenómeno emergente sin repercusión en la esfera pública; b) un movimiento que enfrenta radicalmente a amplios sectores de la sociedad; c) un proyecto fracasado que está dando sus últimos estertores. Cuanto más difusa es la línea entre el pueblo y el contrapueblo, es decir, más aglutinador es el nosotros, mayor potencial ideológico tiene el populismo en cuestión. Por ello sería interesante abordar el fenómeno desde su aspecto consensual. Por ejemplo, en el estudio de los significantes vacíos que, en los tiempos de crisis previos e inmediatamente posteriores a la República, aglutinaban diversas significaciones ideológicas, aun siendo estas últimas radicalmente antagónicas. Un ejemplo es cómo la proclamación de la República fue celebrada por un amplio espectro de la sociedad, incluso por los que, tan solo unos meses después, serían enemigos declarados del proceso republicano, como los fascistas Giménez y Ramos.

Otro de los temas tratados en este estudio es la internacionalización de una ideología antiinternacionalista como el fascismo. La Gaceta fue 
el órgano receptor de una religión política que, al tiempo que atacaba el universalismo, influía universalmente política, ideológica y estéticamente en la esfera internacional (Ben-Ghiat, 2001). En lo que atañe al fascismo como un discurso identitario de rechazo a una minoría étnica, el disparate de Giménez es un canto a la aglomeración de identidades y culturas heterogéneas en un mismo contenedor. Recordemos que la conversión fascista de Giménez comienza por la defensa de una identidad subalterna - lo moro, lo católico - que está siendo sojuzgada por el norte de Europa; un discurso difícilmente comparable con el del posterior nazismo alemán o con el neofascismo actual, que acusa a la inmigración y a los sectores subalternos de los males de la sociedad.

Compartimos que la violencia y la excepción no fueron las características definitorias de esta ideología, sino la construcción de una identidad pública y privada comunitaria (Berezin, 1997). De ella formaron parte las religiones y tradiciones, pero también las nuevas culturas populares. El fascismo fue parte de los procesos de subjetividad que transformaron las sociedades europeas a finales del siglo XIX y principios del XX. En el caso específico del emergente fascismo español, hemos analizado un discurso de celebración de la subjetividad formada por las experiencias de consumo colectivas. Giménez demandaba estetizar toda la esfera pública para dotar a la política de los mecanismos afectivos de los espacios públicos invadidos por una industria cultural foránea. El fascismo de La Gaceta intentó construir un consenso en todos los ámbitos de la esfera pública con la defensa simultánea de A y no-A. La idea de establecer en experiencias puntuales entre los públicos que activaran los mecanismos afectivos para unirlos es quizás una de las paradojas que atravesaron la política del momento. En el artículo hemos analizado la vía estética al fascismo como un proyecto transversal que incluyera a todos los actores de lo nuevo contra lo viejo. La génesis del fascismo español que tanto le debía al disparate ramonista, fue definitivamente rechazada por el fascismo de los años treinta. Recordemos que Ledesma Ramos excluyó a Giménez de La conquista por expresar un pensamiento demasiado literario. Las propias ideas elitistas de Ortega fueron asimiladas por José Antonio Primo de Rivera y el proyecto fascista español, de ser una celebración de la transformación moderna del espacio público, viró en los términos conservadores que, desde antes de comenzar la década de 1920, habían configurado el discurso del miedo contra el bolchevique: 
epítome de masa y la barbarie. Esta metamorfosis se puede ver claramente entre el pseudónimo del Giménez fascista de la vanguardia - Gecé- y el Giménez fascista de la República, apodado Gran Inquisidor.

\section{REFERENCIAS BIBLIOGRÁFICAS}

ANDERSON, A. A. (2002). "Herky, Kerky: Playing Fast and Loose in Giménez Caballero's Hércules jugando a los dados”. En jAgítese bien! New Look at the Hispanic Avant-Garde, R. Hernández y M. T. Pao (eds.), 1-26. Newark: Juan de la Cuesta.

BEN-GHIAT, R. (2001). Fascist Modernities: Italy, 1922-1945. Berkeley: University of California Press.

BEREZIN, M. (1997). Making the Fascist Self: The Political Culture of Interwar Italy. Ithaca, NY: Cornell University Press.

BERMAN, R.A. (1989). Modern Culture and Critical Theory: Art, Politics, and the Legacy of the Frankfurt School. Madison: University of Wisconsin Press.

CAWS, M. A. (2001). "The Poetics of the Manifesto: Nowness and Newness". En Manifesto: A Century of Isms, M. A. Caws (ed.), IXXXXXI. Lincoln: University of Nebraska Press.

CONRAD, S. (2010). Globalisation and the Nation in Imperial Germany. London: Cambridge University Press.

CRUZ, R. (2006). En el nombre del pueblo: República, rebelión y guerra en la España de 1936. Madrid: Siglo XXI.

(2013). "Pueblo, Parapueblo y Contrapueblo en 1931". En Pueblo y nación: homenaje a José Álvarez Junco, J. M. Luzón y F. del Rey (eds.), 59-68. Madrid: Taurus.

ELEY, G. (1992). "Nations, Publics, and Political Cultures: Placing Habermas in the Nineteenth Century". En Habermas and the Public Sphere, C. Calhoun (ed.), 289-339. Cambridge, MA: MIT Press.

GALLEGO MAGALEFF, F. (2005). Ramiro Ledesma Ramos y el fascismo español. Madrid: Síntesis.

GEIST, T. (1980). La poética de la generación del 27 y las revistas literarias: de la vanguardia al compromiso (1918-1936). Madrid: Guadarrama.

GIMÉNEZ CABALLERO, E. (1983). Notas marruecas de un soldado. Barcelona: Planeta (trabajo original publicado en 1923). 
GÓMEZ DE LA SERNA, R. (1921). Disparates. Madrid: Calpe.

GRIFFIN, R. (2007). Fascism and Modernism: The Sense of a Beginning under Mussolini and Hitler. London: Palgrave MacMillan.

GUBERN, R. (1999). Proyector de luna: la generación del 27 y el cine. Barcelona: Anagrama.

HABERMAS, J. (1981). Historia y crítica de la opinión pública. La transformación estructural de la vida pública, Antonio Domenech (trad.). Barcelona: Gustavo Gili (trabajo original publicado en 1962). HIGHFILL, J. (2014). Modernism and its Merchandise: the Spanish Avant-garde and Material Culture, 1920-1930. University Park: The Pennsylvania State University Press.

KRAUEL, R. (2006). "Escatología, fetichismo y bestialismo en Yo, inspector de alcantarillas de Giménez Caballero". Bulletin of Spanish Studies 7, vol. 83, 925-938.

LABANYI, J. (1996). "Women, Asian Hordes and the Threath to the Self in Giménez Caballero's Genio de España”. Bulletin of Hispanic Studies, vol. 73, 377-387.

LACLAU, E. (1977). Politics and Ideology in Marxist Theory: Capitalism, Fascism, Populism. London: NLB.

(2014). Los fundamentos retóricos de la sociedad. Buenos Aires: Fondo de Cultura Económica de Argentina.

LINZ, J. y URQUIZO SANCHO, I. (2006). "El uso religioso de la política y/o el uso político de la religión: la ideología-sucedáneo versus la religión-sucedáneo". Revista Española de Investigaciones Sociológicas 114, 11-35.

MAINER, J-C. (2005). Selección y prólogo a Ernesto Giménez Caballero:, Casticismo, nacionalismo y vanguardia [Antología 19271935]. Madrid: Fundación Santander Central Hispano.

MECHTHILD, A. (2003). Vanguardistas de camisa azul. Madrid: Visor Libros.

MORENO-CABALLUD, LUIS (2010). "Las relaciones interartísticas de vanguardia ante lo político. Un estudio sobre La Gaceta Literaria (1927-1932)". Revista Canadiense de Estudios Hispánicos 3, vol. 34, 429-449.

MOSSE, G. L. (1988). The Culture of Western Europe: The Nineteenth and the Twentieth Centuries. Boulder: Westview Press (trabajo original publicado en 1961). 
NIELAND, J. (2008). Feeling Modern: The Eccentricies of Public Life. Urbana: University of Illinois Press.

NIGEL, D. (1990). "Ernesto Giménez Caballero and Surrealism: A Reading of Yo, Inspector de alcantarillas (1928)". En The Surrealist Adventure in Spain, B. Morris (ed.), 80-100. Ottawa: Dovehouse Editions.

(2002). "The Avant-Garde Oratory of Ramón Gómez de la Serna". En ;Agitese bien! New Look at the Hispanic Avant-Garde, R. Hernández y M. T. Pao (eds.), 77-117. Newark: Juan de la Cuesta.

NUN, J. (1987). "Elementos para una teoría de la democracia: Gramsci y el sentido común”. Revista Mexicana de Sociología 2, vol. 49, 2154.

PAO, M. T. (2010). "Giménez Caballero's Fractured Fairy Tale: El Rendetor mal parido (1926)". En The Popular Avant-Garde, M. R. Silverman (ed.), 135-152. Amsterdam: Rodopi.

PASTOR, M. (1975). Los orígenes del fascismo en España. Madrid: Tucar. PATEMAN, C. (1988). "The Fraternal Social Contract". En Civil Society and the State: New European Perspectives, J. Keane (ed.), 101-128. London: Verso.

PAYNE, S. (1999). Fascism in Spain, 1923-1977. Madison: University of Wisconsin Press.

PINO, J. M. (2004). Del tren al aeroplano: ensayos sobre la vanguardia española. Boulder: Society of Spanish and Spanish-American Studies.

RABATÉ, J-C. (2005). “Introducción”. En En torno al casticismo, M. de Unamuno, 9-104. Madrid: Cátedra.

SALAÜN, S. y SERRANO, C. (2006). Los felices años veinte: España, crisis y modernidad. Madrid: Marcial Pons.

SAZ CAMPOS, I. (2003). España contra España: los nacionalismos franquistas. Madrid: Marcial Pons.

SELVA ROCA DE TOGORES, E. (1999). Ernesto Giménez Caballero: Entre la vanguardia y el fascismo. Valencia: Pre-Textos, 2000. (2005). "Gecé y la Vía estética al Fascismo en España". En Fascismo en España: Ensayo sobre los orígenes sociales y culturales del franquismo, F. Gallego y F. Morente (eds.), 69-108. Madrid: El Viejo Topo.

THOMAS, P. D. (2009). The Gramscian Moment: Philosophy, Hegemony 
and Marxism. Chicago: Haymarket Books.

TORRE, G. (1925). Literaturas europeas de vanguardia. Madrid: Caro Raggio.

UNAMUNO, M. de (2005). En torno al casticismo. Madrid: Cátedra (obra original publicada en 1902).

WERNER, M. (2002). Publics and Counterpublics. Nueva York: Zone Books.

ŽIŽEK, SLAVOJ (1994). “The Spectre of Ideology”. En Mapping Ideology, Slavoj Žižek (ed.), 1-33. New York: Verso.

Recibido el 20 de marzo de 2017.

Aceptado el 12 de mayo de 2017. 